\title{
Sorption of selected antiparasitics in soils and sediments
}

\author{
Andre Patrick Heinrich ${ }^{*} \mathbb{0}$, Timm Zöltzer ${ }^{1}$, Leonard Böhm ${ }^{1} \mathbb{D}$, Manuel Wohde ${ }^{1} \mathbb{B}$, Sara Jaddoudi², \\ Yassine El Maataoui ${ }^{2}$, Abdelmalek Dahchour ${ }^{3}$ and Rolf-Alexander Düring ${ }^{1}$ (D)
}

\begin{abstract}
Background: Veterinary pharmaceuticals can enter the environment when excreted after application and burden terrestrial and aquatic ecosystems. However, knowledge about the basic process of sorption in soils and sediments is limited, complicating regulatory decisions. Therefore, batch equilibrium studies were conducted for the widely used antiparasitics abamectin, doramectin, ivermectin, and moxidectin to add to the assessment of their environmental fate.

Results: We examined 20 soil samples and six sediments from Germany and Morocco. Analysis was based on HPLC-fluorescence detection after derivatization. For soils, this resulted in distribution coefficients $K_{D}$ of $38-642 \mathrm{~mL} / \mathrm{g}$ for abamectin, doramectin, and ivermectin. Moxidectin displayed $K_{D}$ between 166 and $3123 \mathrm{~mL} / \mathrm{g}$. Normalized to soil organic carbon, $\log K_{\mathrm{OC}}$ coefficients were $3.63,3.93,4.12$, and $4.74 \mathrm{~mL} / \mathrm{g}$, respectively, revealing high affinity to organic matter of soils and sediments. Within sediments, distribution resulted in higher $\log K_{\mathrm{OC}}$ of $4.03,4.13,4.61$, and $4.97 \mathrm{~mL} / \mathrm{g}$ for the four substances. This emphasizes the diverse nature of organic matter in both environmental media. The results also confirm a newly reported log $\mathrm{K}_{\text {ow }}$ for ivermectin which is higher than longstanding assumptions. Linear sorption models facilitate comparison with other studies and help establish universal distribution coefficients for the environmental risk assessment of veterinary antiparasitics.

Conclusions: Since environmental exposure affects soils and sediments, future sorption studies should aim to include both matrices to review these essential pharmaceuticals and mitigate environmental risks from their use. The addition of soils and sediments from the African continent (Morocco) touches upon possible broader applications of ivermectin for human use. Especially for ivermectin and moxidectin, strong sorption further indicates high hydrophobicity and provides initial concern for potential aquatic or terrestrial ecotoxicological effects such as bioaccumulation. Our derived $K_{\mathrm{OW}}$ estimates also urge to re-assess this important regulatory parameter with contemporary techniques for all four substances.
\end{abstract}

Keywords: Sorption, Pharmaceuticals, Environmental fate, Environmental distribution, $K_{\mathrm{D}}, K_{\mathrm{OC}}$, Moxidectin, Avermectin, Desorption, Africa

*Correspondence: andre.p.heinrich@umwelt.uni-giessen.de ${ }^{1}$ Institute of Soil Science and Soil Conservation, Research Center for Biosystems, Land Use and Nutrition (iFZ), Justus Liebig University Giessen, Giessen, Germany

Full list of author information is available at the end of the article

\section{Background}

Discovery of the anthelmintic, actinomycete-derived macrocyclic lactones in the 1970s and their advancement into widely available antiparasitic agents came as nothing less than a medical and economic revelation $[1,2]$. Grouped into avermectins and milbemycins, the efficient broad-spectrum endectocides for humans and animals revolutionized treatment of parasitic infestations [3]. Hailed as the 'wonder drug from Japan' [4], the

\section{Springer Open}

(c) The Author(s) 2021. This article is licensed under a Creative Commons Attribution 4.0 International License, which permits use, sharing, adaptation, distribution and reproduction in any medium or format, as long as you give appropriate credit to the original author(s) and the source, provide a link to the Creative Commons licence, and indicate if changes were made. The images or other third party material in this article are included in the article's Creative Commons licence, unless indicated otherwise in a credit line to the material. If material is not included in the article's Creative Commons licence and your intended use is not permitted by statutory regulation or exceeds the permitted use, you will need to obtain permission directly from the copyright holder. To view a copy of this licence, visit http://creativeco mmons.org/licenses/by/4.0/. 
avermectin derivative ivermectin was added to the World Health Organization model list of essential medicines [5]. A valued antiparasitic and safe for human use, ivermectin is also considered as a new malaria vector control tool $[6,7]$. Almost unparalleled in its benefits for human health [8], ivermectin (IVM) was initially developed as a veterinary drug. Similar macrocyclic lactones include the avermectins abamectin (ABA), doramectin (DOR), and eprinomectin (EPR) as well as moxidectin (MOX), a milbemycin agent [3].

The use of pharmaceuticals for animals and humans can be accompanied by the release of drug residues into many environmental compartments. Particularly veterinary medicinal products (VMPs) for livestock, poultry or aquaculture come with the risk of direct drug excretion onto agricultural soils, involuntary application via manure fertilization, and release via runoff or erosion into surface waters. Exposure routes also include drug manufacturing and disposal, and all exposure scenarios raise the question of potential ecotoxicological effects and environmental fate of VMPs [9]. In this regard, sorption of VMPs and contaminants in soils and sediments is a fundamental process which governs the interdependence of fate, bioavailability, and ecotoxicity of a substance $[10,11]$. Monitored by the European Medicines Agency (EMA), VMPs set to be registered in the European Union (EU) must undergo environmental risk assessments [12, 13]. Unfavorable, in this context, for avermectins and MOX is that animals excrete them largely unmetabolized, mainly within days after application, and primarily bound to feces. This feature is ascribed to their hydrophobic nature and an active excretion process via P-glycoprotein $[14,15]$. Despite their extensive use as VMPs, only a limited number of sorption studies exist for macrocyclic lactones. In contrast, hundreds of soil sorption observations are available for major plant protection products, such as atrazine [16]. Reflecting the medical significance of IVM, most studies investigating soil sorption focus on this drug [17-19]. Others investigate ABA [20], EPR [21, 22], or multiple agents at once [23]. To varying degrees, the overarching observation is the tendency of these substances to strongly bind to soil organic matter. This is indicated by a high organic carbon-water partition coefficient $\left(K_{\mathrm{OC}}\right)$. However, with sorption as a fundamental process in soil chemistry [24], the data situation on the fate of these VMPs seems insufficient.

Another complication for environmental risk assessments of the four antiparasitics is the lack of reliable and transparent octanol-water partition coefficients $\left(K_{\mathrm{OW}}\right)$. A routinely assumed order of hydrophobicity (as log $\left.K_{\text {Ow }}\right)$ appears to be: IVM (3.2 [25], presumably used in a marketing request [26]), ABA (4.0 [27] to 4.4 [28]), DOR (4.4 [29]), MOX (4.77 [30], presumably referred to by the
EMA [31]). However, the reported methodology behind these values can be deficient or absent. This is reiterated by the EMA [32] which also cites 4.4 as $\log K_{\text {Ow }}$ for DOR, but addresses the inappropriately used shake-flask method. This methodology is also stated for the 4.4 value of ABA [28] and for MOX [30]. Furthermore, a report funded by the German Environment Agency on environmental properties of antiparasitics, compiled by Römbke et al. [13], concluded that a $\log K_{\mathrm{OW}}$ of 3.22 underestimates this key hydrophobicity indicator for IVM. While this value by Halley et al. [25] is cited frequently [17, 33, 34], the 2019 report implicates at least a 240 -fold increase in hydrophobicity when expressed as $\log K_{\text {OW }}$. In 1989, a method to determine the $\log K_{\mathrm{OW}}$ of potentially highly hydrophobic substances like IVM had not been standardized. It was only introduced in 2006 by the Organisation for Economic Co-operation and Development (OECD) with guideline 123 [35]. Compared to the shake-flask method, this slow-stirring technique is considered more reliable for highly hydrophobic substances [12]. The technique was applied by the Fraunhofer-Institute for Molecular Biology and Applied Ecology (Schmallenberg, Germany), yielding a new $\log K_{\mathrm{OW}}$ of $5.6( \pm 0.3)$ for IVM [13]. This assessment is backed by curated data from the U.S. Environmental Protection Agency predicting a median $\log K_{\mathrm{OW}}$ of 5.41 for IVM's main component IVM B $B_{1 \mathrm{a}}[36]$.

From a regulatory perspective, a $\log K_{\mathrm{OW}}>4$ for VMPs indicates a potential for bioaccumulation to occur in the environment, although multiple criteria need to be considered [12, 37]. In this context, the EMA's Committee for Medicinal Products for Veterinary Use concluded that MOX-containing VMPs for cattle, sheep, and horses might harbor persistent, bioaccumulative, and toxic properties [38]. Fabrega and Carapeto [39] compiled that as a result of environmental concerns, 20 referral procedures of VMPs have been triggered to re-assess environmental risks post-authorization. Six of these products were antiparasitics. It is noteworthy that the European Union is committed to identify knowledge gaps and to address potential environmental risks of pharmaceutical residues and investigate their fate [40].

\section{Non-target effects of macrocyclic lactones}

Extensive reviews by Liebig et al. [33], Lumaret et al. [41], Finch et al. [42], and Junco et al. [43] summarize environmental risks accompanying the unintentional release of macrocyclic lactones and are cause for concern. Acute and chronic effects are observed especially for coprophagous species. Though well documented, knowledge about fate and toxic effects of these drugs on non-target organisms is ever-evolving. Beyond dung and soil, aquatic biota 
can also be harmed if antiparasitics enter surface waters and sediments [44-46].

\section{How would antiparasitics end up in sediments?}

Compelling evidence for this pathway is presented in a field study by Mesa et al. [47] who treated cow herds with IVM and monitored drug concentrations in the wetlands used for grazing. IVM was detected in manure, water, sediment, and macrophytes as well as in wetland invertebrates and fish. Environmental IVM loads increased with animal count and injection frequency. For DOR, Kumirska et al. [48] reported field-concentrations in water, sediment, and fish at a sampled river, with DOR in water exceeding predicted no effect concentrations for Daphnia magna. Since ABA is also used as a pesticide, runoff or erosion from treated fields can enter adjacent water bodies $[49,50]$, enabling transport into sediments. Discharge of antiparasitics into water and sediment, besides direct excretion or transfer from fields, may also be relevant in aquaculture. There, concerns for environmental exposure have been raised for IVM [51], ABA [52], and the ABA derivative emamectin benzoate [53]. When used to control sea lice infestations, IVM can be quantified in low concentrations in marine sediments around fish farms [54]. In water, $\mathrm{DT}_{50}$-values of $<6$ [55] and $15.9 \mathrm{~h}$ [56] have been reported for IVM in simulated sediment/ water systems. This indicates rapid dissipation from aqueous media; presumably binding onto suspended particles and sediment. However, there are no known studies documenting the sorption of macrocyclic lactones in sediments. At the same time, wetlands and sediments are invaluable nurseries for benthic and hyporheic invertebrates as well as emergent aquatic insects (e.g., Ephemeroptera, Plecoptera, Trichoptera) which carry nutrients and biomass to terrestrial habitats $[57,58]$. The drivers of global insect decline are under discussion [59] and it is worth investigating to what extent environmental chemicals and pharmaceuticals may contribute. Although sediments can act as both sinks and sources for contaminants and serve vital functions in aquatic food chains, environmental risk assessment in this compartment is fragmentary [34]. Diepens et al. [60] reiterate this current underrepresentation in regulatory frameworks. If risks of antiparasitics or other VMPs are to be assessed, environmental risk assessment begins with meaningful exposure assessment including a substance's fate in all plausible environmental compartments. Thus, we aim to establish comparable sorption data for antiparasitics in soils and sediments which provide a basis for regulatory decisions.

\section{Experimental approach}

We investigated the sorption of 4 macrocyclic lactones used as antiparasitic VMPs: the avermectins ABA (also used as pesticide), DOR, IVM, and the milbemycin MOX. Sorbates were used simultaneously in each sorption experiment and could be determined at once within an analytical run. The methodology for sorption studies is standardized in OECD guideline 106 [61] to predict substance partitioning in soils. As a novelty, we also performed sorption experiments with six sediments in addition to 20 investigated soil samples. Sorption of these drugs in sediments has not been reported before. We also present, to our knowledge, first-time data from a batch equilibrium study on the sorption of these VMPs in soils and sediments from the African continent.

This work promotes linear modeling with constrained intercepts to derive comparable sorption coefficients that enable robust regulatory decisions. To assess the general hydrophobicity of the antiparasitics and validate our sorption results, we derive and review $K_{\mathrm{OW}}$ estimates from $K_{\mathrm{OC}}$ coefficients.

\section{Materials and methods \\ Soil and sediment samples}

German soil samples (label DE) were provided by the Hessian Agency for Nature Conservation, Environment and Geology (HLNUG). From a pool of samples, 17 were selected for sorption studies. The selection was based on OECD guidance instructions [61]. These samples represent a range of physicochemical properties, soil horizons, textures, sampling depths as well as pasture and crop locations throughout the state of Hesse. Moroccan samples (label MA) were taken in the Gharb Basin region in the northwest of Morocco with a soil auger, collecting the top $20 \mathrm{~cm}$ of soil and sediment. Crop residues on soils were omitted since fields were previously cultivated for various cereals. Bed sediments were sampled along Sebou River (Oued Sebou; MA07 to MA09) and Loukkos river (Oued Loukos; MA04-MA06) with MA04 closest to the Atlantic coast at Merja Zerga lagoon. Before sampling, sediments were cleared of debris. Distance to shore or embankment was 1.5-2 m to sample sediments that were continuously underwater. Table 1 shows the physicochemical properties of soil and sediment samples. In contrast to German samples, the Moroccan samples represent a Mediterranean climate. They are characterized by generally higher $\mathrm{pH}$ values in the carbonate buffer range, resulting from limestone and marl limestone deposits in the basin [62]. Samples were air-dried and sieved to $2 \mathrm{~mm}$. Water content was determined by drying aliquots at $105^{\circ} \mathrm{C}$.

\section{Materials}

ABA and IVM are mixtures of semisynthetic avermectin $\mathrm{B}_{1}$ derivatives. They contain at least $80 \% \mathrm{~B}_{1 \mathrm{a}}$ component ( $\mathrm{C}-25$ s-butyl group) and less than $20 \% \mathrm{~B}_{1 \mathrm{~b}}$ 
Table 1 Physicochemical properties, origins, and sampling depths of soils and sediments for the sorption experiments. Soils labeled DE were taken in Germany; samples labeled MA originated in Morocco

\begin{tabular}{|c|c|c|c|c|c|c|c|c|c|c|}
\hline \multirow[t]{2}{*}{ Label } & \multirow[t]{2}{*}{ Site } & \multirow[t]{2}{*}{ Depth (cm) } & \multirow[t]{2}{*}{$\% O C^{a}$} & \multirow[t]{2}{*}{$C / N^{b}$} & \multirow[t]{2}{*}{$\mathrm{pH}^{\mathrm{c}}$} & \multirow[t]{2}{*}{$\mathrm{CEC}^{\mathrm{d}}$} & \multirow[t]{2}{*}{ Reference soil group ${ }^{e}$} & \multicolumn{3}{|c|}{ Texture (\% w/w) } \\
\hline & & & & & & & & Sand & Silt & Clay \\
\hline DE01 & Crop & $90-120$ & 0.08 & 3.7 & 6 & 19.2 & Luvisol (siltic) & 2 & 61.7 & 36.3 \\
\hline DE02 & Crop & $0-20$ & 5.9 & 20.9 & 7.4 & 19.8 & Regic anthrosol & 59 & 24.7 & 16.3 \\
\hline DE03 & Crop & $65-90$ & 0.73 & 50.2 & 7.6 & 23.2 & Terric anthrosol (stagnic) & 12.2 & 26 & 61.9 \\
\hline DE04 & Crop & $40-100$ & 0.14 & 5.6 & 5.5 & 4.3 & Cambisol (loamic) & 79.4 & 16.4 & 4.2 \\
\hline DE05 & Crop & $60-90$ & 0.15 & 4.8 & 6.3 & 18.9 & Luvisol (siltic) & 2.1 & 63.4 & 34.5 \\
\hline DE06 & Crop & $80-120$ & 0.11 & 2.7 & 6.4 & 11.9 & Planosol & 12.9 & 54.5 & 32.7 \\
\hline DE07 & Crop & $40-60$ & 0.29 & 5.7 & 7.4 & 32.5 & Cambisol (clayic) & 5.3 & 33.4 & 61.2 \\
\hline DE08 & Pasture & $30-55$ & 1 & 6.9 & 6.8 & 22.4 & Vertic cambisol & 3.1 & 49 & 47.9 \\
\hline DE09 & Crop & $0-30$ & 1.8 & 11.3 & 5.9 & 9.9 & Umbrisol & 51.8 & 36.3 & 11.9 \\
\hline DE10 & Pasture & $30-80$ & 0.83 & 7.5 & 6 & 14.7 & Gleyic cambisol (siltic) & 13.5 & 62.5 & 24 \\
\hline DE11 & Pasture & $0-30$ & 2.72 & 8.9 & 5.3 & 27.7 & Vertisol & 4.5 & 65.9 & 29.5 \\
\hline DE12 & Pasture & $0-5$ & 3.15 & 8.9 & 4.4 & 19.9 & Umbrisol (loamic) & 30.8 & 50.2 & 19 \\
\hline DE13 & Pasture & $0-25$ & 3.57 & 8.9 & 5 & 23.9 & Stagnic gleyic cambisol & 4.4 & 62.8 & 32.8 \\
\hline DE14 & Pasture & $0-5$ & 3.89 & 9.7 & 4.6 & 23.5 & Umbrisol (siltic, leptic) & 28.9 & 49.1 & 22 \\
\hline DE15 & Crop & $0-15$ & 6.01 & 17.5 & 6.9 & 27.5 & Terric anthrosol (stagnic) & 53.3 & 26.1 & 20.7 \\
\hline DE16 & Crop & $95-100$ & 0.9 & 68.2 & 7.7 & 21.5 & Terric anthrosol (stagnic) & 10.6 & 27 & 62.5 \\
\hline DE17 & Pasture & $0-10$ & 4.7 & 8.9 & 5.5 & 32.8 & Gleysol & 21.1 & 52.2 & 26.6 \\
\hline MA01 & Crop & $0-20$ & 2.09 & 18.6 & 7.4 & $\mathrm{n} / \mathrm{d}$ & Vertic cambisol & 10.2 & 49.7 & 40.1 \\
\hline MA02 & Crop & $0-20$ & 1.93 & 16.7 & 7.6 & $n / d$ & Vertisol & 4.3 & 28.1 & 67.6 \\
\hline MA03 & Crop & $0-20$ & 1.33 & 18.2 & 7.6 & $n / d$ & Vertisol & 1.7 & 27.8 & 70.6 \\
\hline MA04 & Sediment & $0-20$ & 0.43 & $-^{f}$ & 7.7 & $n / d$ & Not applicable & 95.7 & 1.7 & 2.6 \\
\hline MA05 & Sediment & $0-20$ & 1.23 & 12.5 & 7.7 & $n / d$ & Not applicable & 2.2 & 35.3 & 62.5 \\
\hline MA06 & Sediment & $0-20$ & 0.42 & 26.3 & 7.6 & $n / d$ & Not applicable & 60.2 & 18.9 & 20.9 \\
\hline MA07 & Sediment & $0-20$ & 1.62 & 19.7 & 7.7 & $n / d$ & Not applicable & 3.1 & 32.5 & 64.4 \\
\hline MA08 & Sediment & $0-20$ & 1.38 & 30.1 & 7.5 & $n / d$ & Not applicable & 17.5 & 41.4 & 41.1 \\
\hline MA09 & Sediment & $0-20$ & 0.62 & 50.7 & 7.5 & $n / d$ & Not applicable & 19.5 & 53.4 & 27.1 \\
\hline
\end{tabular}

$n / d$ not determined

${ }^{a}$ Weight percentage of soil/sediment organic carbon, following DIN ISO 10694

${ }^{\mathrm{b}}$ Carbon-to-nitrogen ratio

${ }^{\mathrm{c}} \mathrm{pH}$ measured in a solution of $0.01 \mathrm{~mol} / \mathrm{L} \mathrm{CaCl}_{2}$; following DIN ISO 10390

d Potential cation exchange capacity in cmolc/kg; following DIN ISO 13536

e Reference soil groups according to the World Reference Base for Soil Resources [63] were derived using the German Soil Survey Guidelines, 5th ed. (KA5) and field data from HLNUG. Moroccan soils were characterized on-site. Sediment classification [64] is not provided since gravel content was not available

${ }^{f}$ Not available, minimal $\mathrm{N}$ content made determination impossible

component (C-25 isopropyl group), while DOR holds a sole cyclohexyl group at $\mathrm{C}-25$. Chemically related, the smaller MOX molecule is a semisynthetic derivative of the milbemycin nemadectin, a fermentation product of Streptomyces cyanogriseus, whereas avermectins are derived from Streptomyces avermitilis [3, 65]. Structural differences are shown in Fig. 1.

Antiparasitics were purchased as analytical standards (CAS-no.; product-no., supplier; purity) in powder form: ABA (71751-41-2; 31732-100MG, Sigma-Aldrich; 98.6\%), DOR (117704-25-3; DRE-C13083000, LGC Standards; 96.0\%), IVM (70288-86-7; DRE-CA14488000,
LGC Standards; 96.0\%), and MOX (113507-06-5; DRECA15335000, LGC-Standards; 94.6\%). Acetonitrile (ACN) (20060.320) and propan-2-ol (84881.320P), both $\geq 99.9 \%$ purity, came from VWR International; Calcium chloride dihydrate (102382) from Merck. Derivatization chemicals ( $>99.0 \%$ purity) were bought at Sigma-Aldrich: N-methylimidazole (336092), triethylamine (T0886), trifluoroacetic anhydride (106232), and trifluoroacetic acid (302031). Purified water was prepared with a Milli- ${ }^{\circledR}$ system. We used a CHROMABOND ${ }^{\circledR}$ solid-phase extraction (SPE) system (MACHEREYNAGEL), custom handblown $45 \mathrm{~mL}$ glass centrifuge vials 


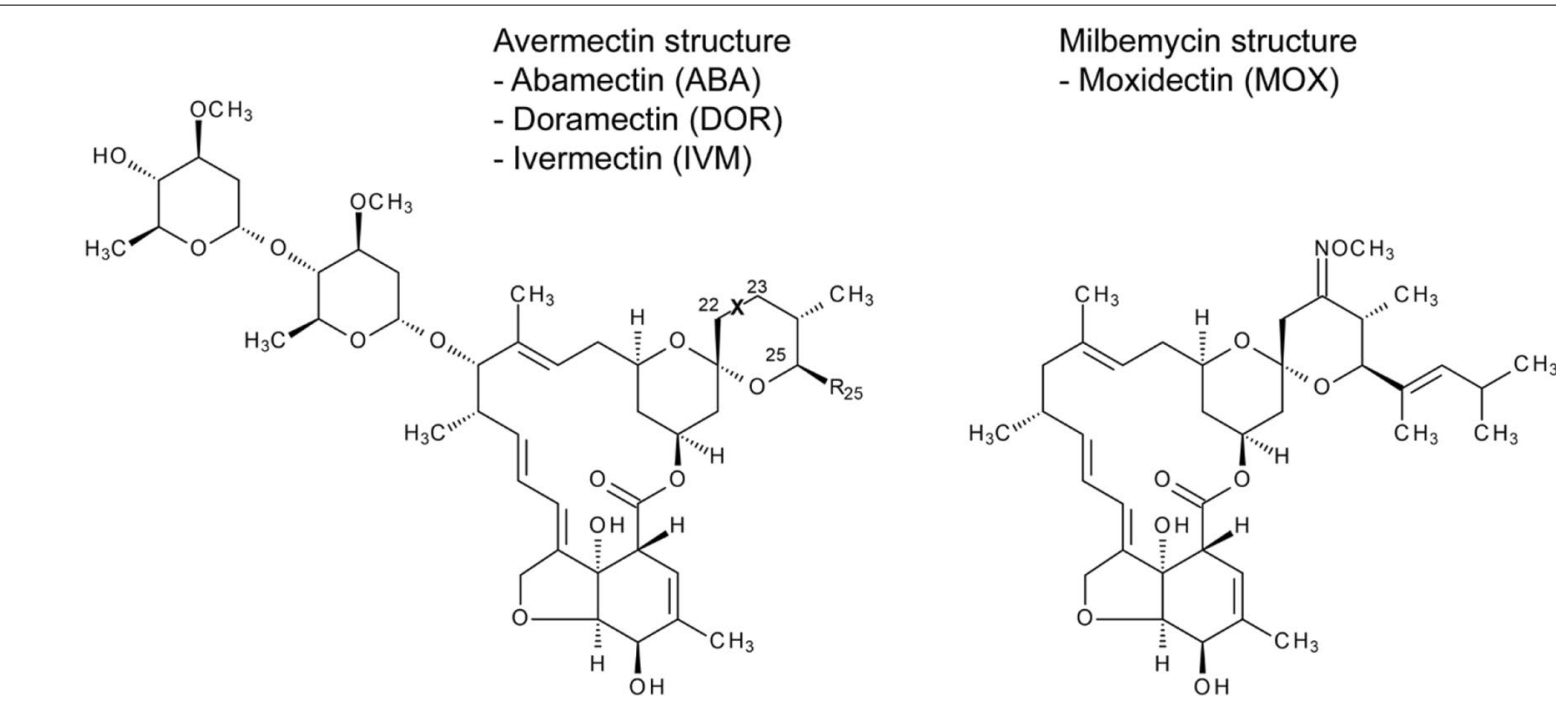

Fig. 1 Chemical structures of the examined antiparasitics. Differences for avermectins (left) are: abamectin (ABA): $\mathrm{X}=\mathrm{double}$ bond, $\mathrm{R}_{25}=\mathrm{CH}\left(\mathrm{CH} \mathrm{H}_{3}\right)$ $\mathrm{CH}_{2} \mathrm{CH}_{3}$ and $\mathrm{CH}\left(\mathrm{CH}_{3}\right)_{2}$; doramectin (DOR): $\mathrm{X}=$ double bond, $\mathrm{R}_{25}=$ cyclohexyl group; ivermectin (IVM): $\mathrm{X}=$ single bond, $\left.\mathrm{R}_{25}=\mathrm{CH}_{(\mathrm{CH}}\right) \mathrm{CH}_{2} \mathrm{CH}_{3}$ and $\mathrm{CH}\left(\mathrm{CH}_{3}\right)_{2}$. The chemically related milbemycin moxidectin (MOX) is shown on the right. Own illustration based on Shoop et al. [3]

with a PTFE-coated silicon seal inside the screw cap, 500 mg Strata C18-E SPE cartridges (8B-S001-HCL, Phenomenex), and $0.45 \mu \mathrm{m}$ PTFE membrane syringe filters (WIC 79145, WICOM).

\section{Sorption experiments}

Experiments were conducted according to OECD guideline 106 [61]. We suspended $1 \mathrm{~g}$ dried soil or sediment with $30 \mathrm{~mL} 0.01 \mathrm{~mol} / \mathrm{L} \mathrm{CaCl}_{2}$ solution in purified water for a $1: 30(\mathrm{w} / \mathrm{v})$ solid/solution ratio. This ratio was elaborated in own preliminary studies and is situated between the ratios of 1:20-:40 (w/v) applied in a comparable study by Rath et al. [23]. Before spiking, solid samples were pre-shaken in the $\mathrm{CaCl}_{2}$ solution for $24 \mathrm{~h}$. Since these antiparasitics represent highly hydrophobic substances, powdered analytical standards were dissolved in ACN to create stock solutions of $4 \times 10^{6} \mu \mathrm{g} / \mathrm{L}$. These solutions were combined in equal proportions for a mixed solution containing $1 \times 10^{6} \mu \mathrm{g} / \mathrm{L}$ of each substance. This was diluted into working solutions to simultaneously spike all drugs in a consistent volume of $30 \mu \mathrm{L} \mathrm{ACN} \mathrm{for}$ a $0.1 \%(\mathrm{v} / \mathrm{v})$ solvent concentration [61]. Sorption in soils DE01 to DE06 was not studied for MOX. In the ongoing sorption study series, we created the following test concentrations in the aqueous phase: $100,200,300,400$, and $500 \mu \mathrm{g} / \mathrm{L}$ (samples DE07-DE17); 100, 200, 300, 500, and $1000 \mu \mathrm{g} / \mathrm{L}$ (MA01-MA09); 500, 1000, 1500, 2000, and $2500 \mu \mathrm{g} / \mathrm{L}$ (DE01-DE06). After spiking, solutions were shaken for $48 \mathrm{~h}$ (sorption equilibrium time) while glass vials were wrapped with aluminum foil to prevent possible photodegradation. Controls contained soil/sediment samples with $\mathrm{CaCl}_{2}$ solution or $\mathrm{CaCl}_{2}$ solution spiked with antiparasitics absent of soil/sediment. An experimental duration of $48 \mathrm{~h}$ was selected to reach apparent sorption equilibrium between macrocyclic lactone concentrations in soil/sediment and the aqueous phase. This was based on own preliminary kinetic studies and is supported by comparable experiments. [17, 20]. An exemplary desorption assessment was performed after $72 \mathrm{~h}$ and is briefly addressed in the discussion. Systems were equilibrated using a horizontal lab shaker (KS-10 Swip, Edmund Bühler $\mathrm{GmbH}$ ) at $250 \mathrm{rpm}$. German samples were spiked in duplicates, Moroccan samples in triplicates. All steps were performed under ambient laboratory conditions at $21 \pm 1{ }^{\circ} \mathrm{C}$.

\section{Sample processing}

Analytical procedures were based on Wohde et al. [56, 66] and adapted as follows: SPE cartridges were conditioned with $10 \mathrm{~mL}$ propan-2-ol followed by $10 \mathrm{~mL}$ of a $1: 3 \mathrm{mix}-$ ture $(\mathrm{v} / \mathrm{v})$ of propan-2-ol and purified water. At $48 \mathrm{~h}$ shaking time, samples were centrifuged at $2820 \mathrm{~g}$ for $30 \mathrm{~min}$ and $25 \mathrm{~mL}$ supernatant were added to a reservoir atop the SPE cartridges along with $8.333 \mathrm{~mL}$ propan-2-ol and $25 \mu \mathrm{L}$ triethylamine. Dried cartridges were eluted with $10 \mathrm{~mL}$ propan-2-ol. Eluates were evaporated to dryness under an $\mathrm{N}_{2}$ stream at $60{ }^{\circ} \mathrm{C}$. For reconstitution, $1000 \mu \mathrm{L}$ ACN were added to each vial. Vials were then sonicated for $15 \mathrm{~min}$, horizontally shaken $(250 \mathrm{rpm})$ for $30 \mathrm{~min}$, and again sonicated for $15 \mathrm{~min}$. Between each step, samples were vortexed for $30 \mathrm{~s}$. Subsequently, samples were derivatized and quantified by HPLC-fluorescence detection 
on an Agilent 1200 HPLC system as elaborated by Wohde et al. [66]. This was applied for all four test substances with $40 \mu \mathrm{L}$ injection volume and a shorter gradient elution. Mobile phases were A (purified water) and $\mathrm{B}$ (ACN); flow $0.3 \mathrm{~mL} / \mathrm{min}$; gradient $0-10 \mathrm{~min}, 88-100 \%$ B; $10-11 \min , 100 \%$ B; $11-20$ min $100-88 \%$ B. Since a broad range of sample characteristics and expected sorption was covered in the overall study series, we used different linear calibration sets of mixed standard solution with at least seven calibration standards per individual calibration series. All calibration curves displayed a linear response with $R^{2}>0.998$.

\section{Deriving distribution coefficients}

Soil and sediment samples were evaluated alike. Evaluation followed OECD guideline 106 [61]. The distribution coefficient $K_{\mathrm{D}}$ is defined as the ratio of substance concentration in the solid-phase $C_{\mathrm{s}}(\mathrm{eq})$ and the substance concentration in the aqueous-phase $C_{\mathrm{aq}}(\mathrm{eq})$ at equilibrium with the equation:

$$
K_{\mathrm{D}}=\frac{C_{\mathrm{s}}(\mathrm{eq})}{C_{\mathrm{aq}}(\mathrm{eq})},
$$

where $C_{\mathrm{s}}(\mathrm{eq})$ is expressed in $\mu \mathrm{g} / \mathrm{g}, C_{\mathrm{aq}}(\mathrm{eq})$ in $\mu \mathrm{g} / \mathrm{mL}$, and the $K_{\mathrm{D}}$ in $\mathrm{mL} / \mathrm{g}$. The measured $C_{\mathrm{aq}}$ (eq) was then used to indirectly estimate the remaining amount of substance in the solid phase, delivering $C_{\mathrm{s}}$ (eq). While Eq. (1) holds true for a single set of a solid and an aqueous phase, we derived the $K_{\mathrm{D}}$ for each sample by plotting all concentrations and replicates. We obtained the $K_{\mathrm{D}}$ as the slope of a linear regression with the $y$-intercept constrained. The decision of constraining the y-intercept was deliberate and relied on Chappell et al. [67] who concluded that only if consistency was imposed on a set of linear equations, distribution coefficients could be compared among different soils which is an aim of this work. While different concepts exist to describe distribution with sorption isotherms, such as linear models or nonlinear approaches with the Freundlich and Langmuir equation, they remain of theoretical nature. Linear models assume proportional increase of sorbed amounts with increasing adsorbate concentration in the aqueous phase. They consider no competition of solutes which is a relevant aspect when investigating four substances at once [24]. A constant slope reflects that sorbates have much higher affinity for sorbents than for the aqueous phase. This benefits low and environmentally relevant concentrations and Rao and Jessup [10] suggest the use of linear isotherms if agricultural applications or pathways are considered. Nonlinear sorption isotherms from studies with five test concentrations [61] may appear insufficient to produce a reliable, steady intercept that is not overstated. Especially the lowest concentration step can entail the most uncertainty and could strongly affect the intercept. Organic carbon $(\mathrm{OC})$ is considered largely responsible for sorptive properties in soils [68]. Thus, the $K_{\mathrm{D}}$ is normalized to this parameter to derive the $K_{O C}$ in $\mathrm{mL} / \mathrm{g}$. The $K_{\mathrm{OC}}$ can serve as a tool to estimate the mobility of a chemical in soil [69] and is derived with the equation:

$$
K_{\mathrm{OC}}=\frac{K_{\mathrm{D}}}{f_{\mathrm{OC}}}
$$

where $f_{\mathrm{OC}}$ is the $\mathrm{OC}$ fraction of the soil/sediment [70] expressed as weight percentage of soil/sediment OC $(\% \mathrm{OC})$. Here, $f_{\mathrm{OC}}$ was chosen over $\% \mathrm{OC}$ to directly plot $f_{\mathrm{OC}}$ vs. $K_{\mathrm{D}}$ values and derive the $K_{\mathrm{OC}}$ of multiple soils as slope of a linear regression. Both Freundlich and Langmuir models can make determining a tangible $K_{\mathrm{OC}}$ impractical. Further, as recommended in OECD guideline 106, we excluded soil samples with $<0.3 \%$ OC from $K_{\mathrm{OC}}$ calculations for which we selected 13 (12 for MOX) out of 20. Figures 2, 3 are calculated and created using OriginPro 2020b (OriginLab Corporation, Northampton, MA, USA).

\section{Method validation}

Limit of detection (LOD) and limit of quantification (LOQ) for the HPLC-method were estimated according to recommendations in guideline Q2(R1) by the International Council for Harmonisation of Technical Requirements for Pharmaceuticals for Human Use [71]. Based on the five lowest calibration standards $(2,5,10,50$, and $100 \mu \mathrm{g} / \mathrm{L})$, we used the calibration curve slope $(m)$ and standard deviation $(\sigma)$ of the response expressed as standard error of the y estimate (derived with the STEYX function in Microsoft Excel 2019). LOD is expressed as $3.3 \times \sigma / \mathrm{m}$ and LOQ as $10 \times \sigma / \mathrm{m}$. These results are given in Table 2. Further shown is the total number of replicates from all batch studies (soils and sediments) which were above the LOQ. Control samples did not reveal

Table 2 Limit of detection (LOD) and limit of quantification (LOQ) for antiparasitics in sampled aqueous phases of sorption studies using area response of 2, 5, 10, 50, and $100 \mu \mathrm{g} / \mathrm{L}$ calibration steps in $n=3$ measurements with $R^{2}$. Analyte concentration enrichment during sample processing is

\begin{tabular}{|c|c|c|c|c|}
\hline & $\begin{array}{l}\text { Correspond } \\
\text { sampled aq }\end{array}$ & $\begin{array}{l}\text { concentratic } \\
\text { bus phase } C_{a c}\end{array}$ & $\begin{array}{l}n \text { the } \\
\text { l) }\end{array}$ & $\begin{array}{l}\text { Samples } \\
\text { above LOQ }\end{array}$ \\
\hline & $\operatorname{LOD}(\mu \mathrm{g} / \mathrm{L})$ & $\mathrm{LOQ}(\mu \mathrm{g} / \mathrm{L})$ & Mean $R^{2}$ & \\
\hline ABA & 0.53 & 1.61 & 0.996 & 100 \\
\hline DOR & 0.56 & 1.71 & 0.995 & 100 \\
\hline IVM & 0.55 & 1.66 & 0.996 & 99.0 \\
\hline MOX & 0.67 & 2.02 & 0.993 & 99.2 \\
\hline
\end{tabular}
considered 
irregularities in terms of analyte losses or cross-contamination nor relevant sorption to surfaces of laboratory equipment. Pre-empting the results section, the concentration range in which substances were found across all samples reveals a hierarchy in their tendency to remain in the aqueous phase. The trend in lowest $C_{\mathrm{aq}}(\mathrm{eq})$ in $\mu \mathrm{g} / \mathrm{L}$ in any replicate was ABA (1.2), DOR (0.49), IVM (0.31). Conversely, the order for highest $C_{\text {aq }}$ (eq) was IVM (785), DOR (812), ABA (986). MOX conflicts this trend (0.62$247 \mu \mathrm{g} / \mathrm{L})$, but was not used in soils with low $\% O C$ where a high $C_{\mathrm{aq}}(\mathrm{eq})$ is suspected.

We monitored the stability of fluorescent ABA, DOR, IVM, and MOX derivates for $20 \mathrm{~min}, 24,48$, and $72 \mathrm{~h}$ after derivatization $(n=6)$. After a slight decrease over time, $72 \mathrm{~h}$ average fluorescence recovery remained at 86.5, 85.1, 92.7, and 89.3\% for ABA, DOR, IVM, and MOX derivates compared to $20 \mathrm{~min}$. Consistently, samples were measured within $24 \mathrm{~h}$ after derivatization. Measurements of up to $72 \mathrm{~h}$ after derivatization of calibration standards and samples should not impair overall results.

Although the HPLC protocol yields favorable separation, a quality control was performed. Chromatograms of standard solutions containing only a single analyte showed minor fluorescence at retention times other than the main peak. This is presumably attributed to the purity (94.6-98.6\%) of purchased standards. IVM and MOX peaks showed no overlap with impurities of other analytes. We found a fluorescence increase for ABA and DOR main peaks of 1.1 and $3.4 \%$ and downscaled these accordingly. ABA and IVM sorption results will represent their major (>96\%) $\mathrm{B}_{1 \mathrm{a}}$ component.

For additional method validation, a standard soil (LUFA 2.2) was purchased from LUFA Speyer (loamy sand; $1.61 \%$ OC; $0.18 \%$ nitrogen; pH $5.6(0.01 \mathrm{~mol} / \mathrm{L}$ $\mathrm{CaCl}_{2}$ ); CEC $\left.8.5 \mathrm{meq} / 100 \mathrm{~g}\right)$. Therewith, we performed a mass balance determination [61] at $300 \mu \mathrm{g} / \mathrm{L}$ spiked concentration. Liquid phase extraction was performed with the presented SPE method. Soils and vessel walls were extracted two times with $5 \mathrm{~mL} \mathrm{ACN}$. The overall recovery of spiked antiparasitics ranged from 86 to $118 \%$ for the four substances. Mean recoveries $( \pm$ SD, $n=4)$ were: ABA 90.8 (4.1), DOR 107 (4.1), IVM 112 (2.1), and MOX $115.9 \%$ (1.6). This indicates that there is no relevant degradation of analytes within $48 \mathrm{~h}$ of shaking. Test substances can be considered to be stable. Determination with the indirect method [61] should thus be appropriate. This is in line with previous mass balance and stability reports on the sorption of avermectins [19-21]. The same soil and drug concentration were used to compare sorption of all four analytes with sorption when only IVM is added. IVM slope $K_{\mathrm{D}}( \pm \mathrm{SE}, n=4)$ was 532 (12) with only IVM and $471(26) \mathrm{mL} / \mathrm{g}$ with four analytes. Under these conditions only negligible competition in sorption is indicated when all four substances are spiked at once. Additional information on the method validation is provided in the Additional file 1.

\section{Results and discussion \\ Sorption in soils}

Batch equilibrium studies were evaluated with linear sorption isotherms which served for calculation of $K_{\mathrm{D}}$ values. Plotting soil $K_{\mathrm{D}}$ against $f_{\mathrm{OC}}$ resulted in Fig. 2. It shows the $K_{\mathrm{OC}}$ as the slope of the linear regression through 13 (12 for MOX) selected soils with the intercept constrained which creates a narrowing confidence corridor. For soils included in this regression, $K_{D}$ values ranged from 38 to 211 (ABA), 63 to 428 (DOR), 76 to 642 (IVM), and 166 to $3123 \mathrm{~mL} / \mathrm{g}$ (MOX). This dispersion characterizes the variability of the selected soils. Individual $K_{D}$ values are listed in the Additional file 1.

The detail area of Fig. 2 shows soils with less than 0.3\% OC. The linear regressions with $95 \%$ confidence bands of the used dataset fall below the individual $K_{\mathrm{D}}$ values for each substance in this region of low $f_{\mathrm{OC}}$. Recommended in OECD guideline 106, the procedure of removing these soils from $K_{\mathrm{OC}}$ calculations is corroborated by Krahe et al. [72] who also showed that below $0.3 \%$ soil OC linear model approaches become uncertain. They argue that at low concentrations, the accuracy of $\mathrm{OC}$ analyses could be reduced and that other sorption surfaces could become more relevant. It appears reasonable to assume that with little OC available, substances more likely sorbed to other available surfaces like clay, silt or dissolved organic matter, therefore displaying a $K_{D}$ above the regression. Of the thus five excluded soils, four displayed above average clay or silt concentrations among all 20 soils which could explain their relatively high sorption. Only DE04 with the highest sand content and low cation exchange capacity contradicts this rationale. With the presented parameters, its sorption behavior remains elusive. Both DE15 and DE02 showed relatively low $K_{\mathrm{D}}$ values and contradicted the linear trend. This could be attributed to the fact that both samples originated from soil horizons with only moderately decomposed organic material and DE15 displayed stagnic properties. However, quality and detailed composition of organic material and its influence on the $\mathrm{pH}$ would have to be considered. Less decomposed organic material can harbor more hydrophilic groups, indicated by a lower elemental H/O ratio [73]. More available hydrophilic groups can explain lower sorption for hydrophobic substances if $\mathrm{OC}$ is the main sorbent. Thus, we further excluded soils DE15 and DE02 with OC contents of 6.0 and $5.9 \%$ and in total seven out of 20 soils for the $\mathrm{K}_{\mathrm{OC}}$ calculation which are shown with hollow symbols. In a meta-analysis on atrazine sorption, 


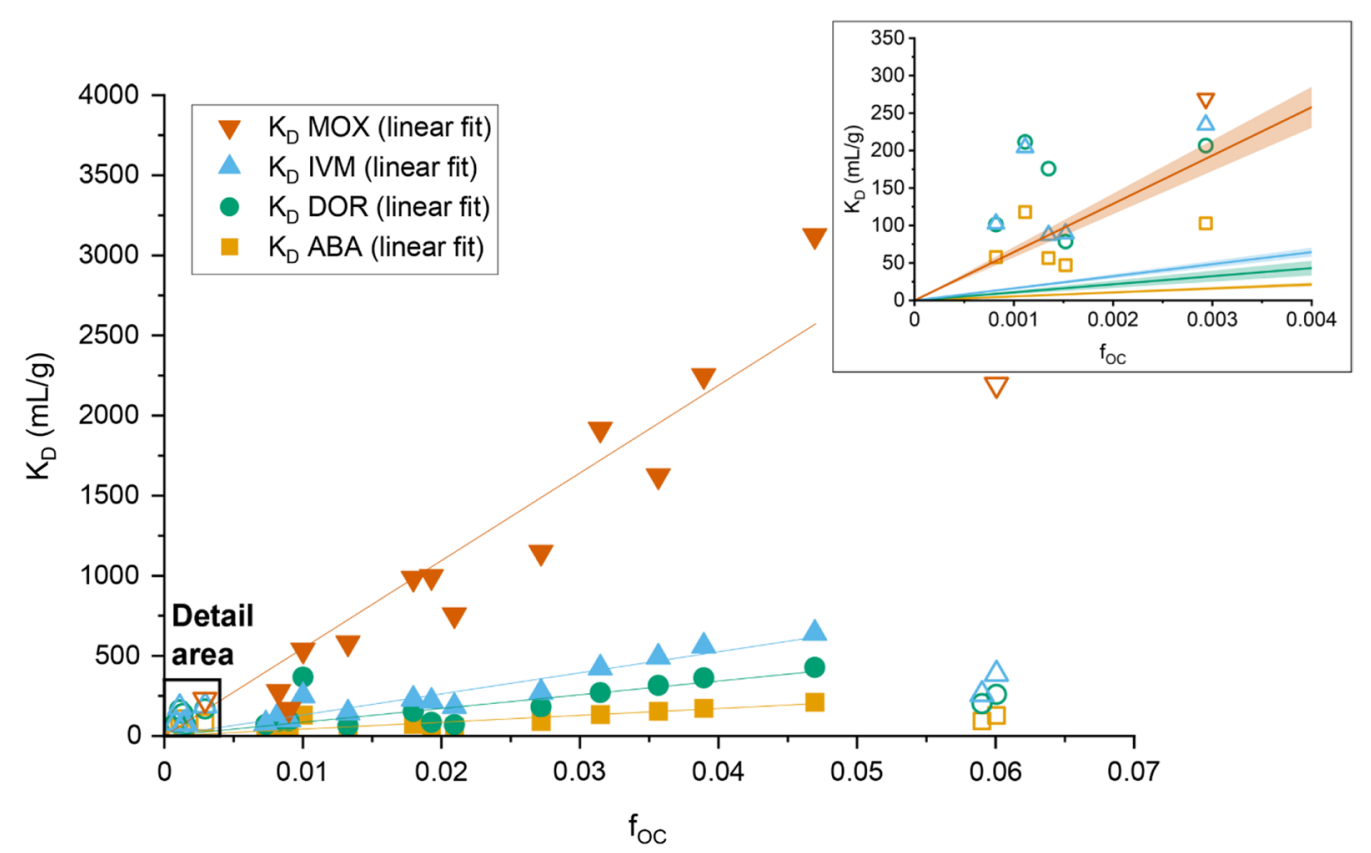

Fig. 2 Experimentally determined $K_{\mathrm{D}}$ values of 20 soil samples from Germany and Morocco plotted against $f_{\mathrm{OC}}$ (organic carbon fraction) of each soil. Symbols, regression lines (and 95\% confidence bands in the detail area, top right) depict results for abamectin (ABA), doramectin (DOR), ivermectin (IVM), and moxidectin (MOX). Hollow symbols of the same shape and color represent $K_{\mathrm{D}}$ values that were not included in $K_{\mathrm{OC}}$ calculations. See Additional file 1 for all $K_{D}$

Ou et al. [16] concluded that soils with OC $>6 \%$ should be considered as outliers.

Next, Table 3 displays derived cumulated $K_{\text {OC }}$ values using the previously selected 13 soils. We distinguish between the preferable description as slope of a linear regression through the origin (RTO) and an ordinary least squares (OLS) regression with floating intercept. The table further shows $K_{\mathrm{OC}}$ values expressed as the mean and median of individual $K_{\mathrm{OC}}$ values from soils considered suitable for the linearized approach. This illustrates the ambiguity that comes with the need to define a single value which quantifies a substance's sorption behavior.
Linearized RTO $\log K_{\mathrm{OC}}$ were 3.63 (ABA), 3.93 (DOR), 4.12 (IVM), and $4.74 \mathrm{~mL} / \mathrm{g}$ (MOX). For the OLS model, the $\log K_{\mathrm{OC}}$ were $3.58,3.87,4.13$, and $4.82 \mathrm{~mL} / \mathrm{g}$, respectively. The OLS y-intercepts amounted to 15.1 (ABA), 32.2 (DOR), - 8.8 (IVM), and - $349.9 \mathrm{~mL} / \mathrm{g}$ (MOX). This partially reflects the increasing steepness of sorption from ABA $<$ DOR $<$ IVM $<<$ MOX. However, the negative $y$-intercepts for IVM and MOX may also illustrate the shortcomings of an OLS regression with a floating intercept since negative sorption at zero or minimal OC would be implausible.

The $R^{2}$ for the RTO $K_{\mathrm{OC}}$ were 0.94 (ABA), 0.85 (DOR), 0.97 (IVM), and 0.97 (MOX). However, since a

Table 3 Summarized $K_{O C}$ data for the selected soils ( $n=13$ for ABA, DOR, IVM; $n=12$ for MOX) showing a linearized and averaged approach to define a cumulated soil $K_{\mathrm{OC}}$. All values in $\mathrm{mL} / \mathrm{g}$

\begin{tabular}{|c|c|c|c|c|c|}
\hline \multirow[t]{2}{*}{ Substance } & \multicolumn{2}{|c|}{ 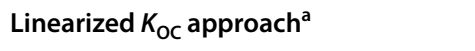 } & \multicolumn{3}{|c|}{ Averaged $K_{\mathrm{OC}}$ approach } \\
\hline & RTO $K_{\mathrm{OC}}(\mathrm{SE})$ & OLS $K_{\mathrm{OC}}(\mathrm{SE})$ & Mean (SD) $)^{b}$ & Median & Range (min-max $K_{\mathrm{oc}}$ ) \\
\hline ABA & $4286(319)$ & $3769(651)$ & $4941(2581)$ & 4343 & $2653-13,032$ \\
\hline DOR & $8574(1025)$ & 7470 (2134) & $10,133(8334)$ & 8866 & $3423-36,683$ \\
\hline IVM & $13,139(611)$ & $13,441(1288)$ & $13,266(4137)$ & 12,795 & $8850-25,109$ \\
\hline MOX & $54,721(3136)$ & $66,506(5666)$ & $47,046(13,356)$ & 48,555 & $18,493-66,522$ \\
\hline
\end{tabular}

${ }^{\mathrm{a}}$ Expressed as slope of a linear regression of $K_{\mathrm{D}}$ vs. $f_{\mathrm{OC}}( \pm$ standard error of the regression slope) with the y-intercept forced through zero (RTO linear regression through the origin) or floating (OLS ordinary least squares)

${ }^{\mathrm{b}}$ Arithmetic mean with standard deviation (SD) 
constrained y-intercept skews $R^{2}$ calculations it makes it less meaningful and complicates comparison with $R^{2}$ obtained from OLS. Instead, the standard error (SE) of both regressions can be an alternative measure [74]. In this regard, the RTO $K_{\mathrm{OC}}$ appears to provide a more suitable fit. The $R^{2}$ of the OLS $K_{\mathrm{OC}}$ were 0.75 (ABA), 0.53 (DOR), 0.91 (IVM), and 0.93 (MOX). This reflects the wide spread of individual $K_{\mathrm{D}}$ values, especially for ABA and DOR. Thus, it is conceivable that sorption of the more hydrophobic IVM and MOX is better explained with the $K_{\mathrm{OC}}$ concept than for the slightly less hydrophobic ABA and DOR. This deduction is reiterated by Tolls [11] for hydrophobic VMPs and their soil interactions in general. For the core range of $0.3-4.7 \%$ OC in soils, the relation between $\mathrm{OC}$ and distribution is well explained for IVM and MOX. This range also broadly represents the \%OC found in most European agricultural topsoils [75]. In low OC environments, other surfaces such as clay are more relevant, while especially with a higher \%OC, organic matter quality and composition appear to skew the $\mathrm{K}_{\mathrm{D}}-\mathrm{f}_{\mathrm{OC}}$ relation. Lastly, we applied a Box-Cox transformation on all soil $K_{\mathrm{D}}$ values to ensure normal distribution and subjected them to a multiple linear regression with OriginPro 2020b to compare them to soil properties from Table 1. With $\alpha=5 \%$, soil OC demonstrated significant influence on ABA, DOR, and IVM $K_{\mathrm{D}}$. C/N and $\mathrm{pH}$ were significant predictors for $\mathrm{ABA}$ and DOR $K_{\mathrm{D}}$. The complete output is listed in the Additional file 1. While $\mathrm{OC}$ is a convenient and established estimator for contaminant sorption in soils, it is plausible that, together with the $\mathrm{pH}$, the detailed composition of organic matter would also predict sorption in soils once a large enough number of samples is studied.

\section{Broader context of soil sorption}

Litskas et al. [22] stressed that avermectin sorption in soils determines bioavailability for non-target organisms. They suspected that once incorporated into soil, avermectins could withstand degradation and possibly accumulate if microbial activity was reduced due to unfavorable abiotic conditions or biocides [76]. This could be true for soils where agriculturally used biocides or disinfectants are spread with manure, potentially combined with antibiotics, antiparasitics, or other VMPs. Occurrence and transformation of biocides in manure and their fate in soils are only marginally investigated [77, 78]. Moreover, biocide release into the environment could increase due to the SARS-CoV-2 pandemic [79].

For IVM, promising mass drug administrations to livestock to target malaria vectors [80] may increase drug release onto soils. If this approach is complemented with human IVM treatments [7, 81], aquatic pathways in sewage systems could be subject to monitoring and analysis.
This makes thorough drug exposure and fate assessments necessary. And it signals the need to include soils from the African continent and other previously neglected regions into sorption studies to provide most-needed One-Health solutions. To realize a safe and sustainable agricultural production, revised herd management strategies may also provide ecological and economic benefits while reducing stress on dung arthropod communities [82]. A sophisticated proposal for post-authorization monitoring of antiparasitics already exists [83] and a deliberate drug use could further address emerging anthelmintic resistances [84].

Lastly, the observed sorption in soils is in line with reported distribution coefficients for $\mathrm{ABA}$ of $K_{\mathrm{D}}$ $10-161 \mathrm{~mL} / \mathrm{g}$ [85] and for IVM of $K_{\mathrm{D}} 57-396 \mathrm{~mL} / \mathrm{g}$ [17]. Rath et al. [19] described IVM sorption $K_{\mathrm{D}}$ between 60 and $1953 \mathrm{~mL} / \mathrm{g}$ and desorption $K_{\mathrm{D}}$ between 47 and $431 \mathrm{~mL} / \mathrm{g}$. Previous $\mathrm{ABA} K_{\mathrm{OC}}$ ranged from 1495 to $7893 \mathrm{~mL} / \mathrm{g}$ [28]. For IVM, $K_{\mathrm{OC}}$ between 4000 and $25,800 \mathrm{~mL} / \mathrm{g}$ were documented [17] and for MOX between 18,000 and $41,000 \mathrm{~mL} / \mathrm{g}$ [30]. However, it is difficult to compare $K_{\mathrm{D}}$ data from linearly modeled sorption experiments with other studies which used Freundlich sorption isotherms to produce a $K_{\mathrm{F}}$. Although nonlinear models can provide a better fit, they lack comparability, especially when the Freundlich exponent differs significantly from 1. Based on Rath et al. [19] we performed a desorption experiment using the LUFA 2.2 standard soil by replacing the analyzed liquid phase with the same amount of fresh $\mathrm{CaCl}_{2}$ solution and shaking for $72 \mathrm{~h}$. Mean percentual desorption $( \pm \mathrm{SD}, n=6)$ at a single concentration amounted to: ABA 4.6 (0.3), DOR 3.5 (0.1), IVM $2.9(0.1)$, and MOX $2.6(0.1) \%$. While only a fragmentary approximation for a full desorption study [61], these percentages compliment the sorption data of the four antiparasitics in soils and indicate mostly irreversible sorption processes.

\section{Sorption in sediments}

Compared to soils, sediment $K_{\mathrm{D}}$ showed a range from 21 to 296 (ABA), 35 to 376 (DOR), 53 to 915 (IVM), and 87 to $2326 \mathrm{~mL} / \mathrm{g}$ (MOX). Less indicative, mean sediment $K_{\mathrm{D}}$ $(\mathrm{mL} / \mathrm{g})$ were higher for ABA (106 vs. 98) and IVM (394 vs. 287) but lower for DOR (137 vs. 197) and MOX (861 vs. 1196). The distribution of all sediment $K_{\mathrm{D}}$ results is illustrated in Fig. 3 which again reveals the strongest sorptive behavior by MOX.

Although sediment MA06 had the lowest \%OC (0.42), it displayed the highest $K_{\mathrm{D}}$ values for ABA, DOR, and IVM, and the third-highest for MOX among the six sediments. Since it cannot be inferred from the limited sediment sample size if this behavior is an outlier or part of an unknown trend, we removed MA06 from further 


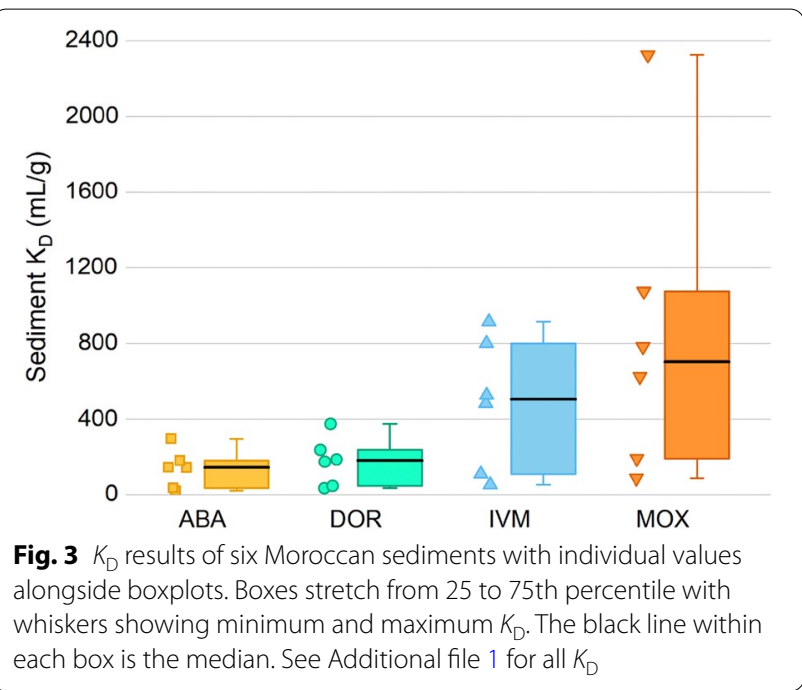

calculations. However, parameters other than \%OC could be more relevant for sorption in MA06. In comparison, MA04 with the highest sand content and similarly low \%OC expectedly proved to be least prone for sorption. Because sediments also had a lower average \%OC than soils, the resulting $\log K_{\mathrm{OC}}$ of 4.03 (ABA), 4.13 (DOR), 4.61 (IVM), and 4.97 (MOX) $\mathrm{mL} / \mathrm{g}$ were higher compared to soils when using an RTO. As was observed in soils, sediment $\log K_{\mathrm{OC}}$ also ranked $\mathrm{MOX}>\mathrm{IVM}>\mathrm{DOR}>$ $\mathrm{ABA}$, again reflecting the diverging behavior of MOX, presumably due to structural differences to the avermectins. Higher mean $K_{\mathrm{OC}}$ in sediments than in soils were also documented by Chiou and Kile [70]. For a larger sample size, they described that for carbon tetrachloride and 1,2-dichlorobenzene mean sediment $K_{\mathrm{OC}}$ were about 1.7 times higher than soil $K_{\mathrm{OC}}$. Adding to that, we report sediment $K_{\mathrm{OC}}$ to soil $K_{\mathrm{OC}}$ ratios of 1.8 for ABA, 1.2 for DOR, 2.4 for IVM and 1.4 for MOX when comparing five selected sediments and 13 selected soils. Higher sediment than soil $K_{\mathrm{OC}}$ with a factor of about 1.9 was also shown for the antiparasitic drug albendazole by Mutavdžić Pavlović et al. [86]. Chiou and Kile [70] reported that during sedimentation, organic components fractionate and polar components dissolve over time, leaving behind hydrophobic components in the bed sediment.

Change of organic matter composition during sedimentation is known to affect sorption especially for nonionic compounds [73] and could be relevant for the examined antiparasitics. Their strong sorption in sediments is worrisome for inhabitants of these ecosystems, exemplarily shown by chronic effects of IVM on benthic invertebrates [45]. Adverse effects on sediment-dwelling non-target organisms must especially be considered when avermectins are applied in aquaculture [53]; an industry directly burdening aquatic ecosystems with VMPs [9] which may then pass into sediments. Davies et al. [34] expected risks for polychaetes living below or around fish cages and an IVM half-life in marine sediment $>100$ days. Prasse et al. [55] reported a comparable timeframe and documented high persistence of IVM in a simulated sediment/water system $\left(\mathrm{DT}_{50}=127\right.$ days $)$ driven by strong sorption in the sediment. Mesocosm experiments by Roberts et al. [87] with trout farm effluents showed moderate toxicity to benthic macroinvertebrates and no sensitive taxa were found in the receiving stream. The study, however, was performed unrelated to the use of pharmaceuticals. However, IVM is indicated to be highly persistent in sediments [44] and to possibly accumulate in aquatic organisms $[47,88]$. This further encourages thorough, regulated exposure and risk assessments for hyporheic and benthic taxa. Sediment classification [64] and organic matter composition may also be relevant variables to predict $K_{\mathrm{D}}$ data.

\section{Relationship between $K_{O C}$ and $K_{o w}$}

The $K_{\mathrm{OC}}$ and $K_{\mathrm{OW}}$ of a substance are inextricably linked since both serve the concept that $\mathrm{OC}$ and 1-octanol act as hydrophobic counterparts to a chemical [89]. The $K_{\mathrm{OW}}$ is also the most frequently used indicator of hydrophobicity of a chemical and an essential parameter in toxicology and environmental sciences [90]. Over time, different concepts were developed to predict the sorption of organic chemicals in soils based on molecular properties. We ventured to predict the $\log K_{\mathrm{OW}}$ of the studied antiparasitics if the RTO $\log K_{\mathrm{OC}}$ were the only available variable. For this, we applied well-known concepts [68, 91-93] which aim to quantify the relationship between $\log K_{\mathrm{OC}}$ and $\log K_{\mathrm{OW}}$ based on $\log K_{\mathrm{OW}}$ data. These predictions are depicted in Table 4. While it is apparent that conditions and limitations apply to these concepts, our decent set of $\log K_{\mathrm{OC}}$ data should allow for an estimate of the antiparasitics' hydrophobicity when expressed as $\log K_{\text {OW. }}$. However, these estimations must not be overstated. A $K_{\mathrm{OW}}$ is easier to obtain experimentally than performing complex sorption batch studies. Hence, applying the slow-stirring method from OECD guideline 123 [35] would yield more accurate $\log K_{\text {OW }}$ data for the studied VMPs. The $\log K_{\text {OW }}$ of 5.6 ( \pm 0.3$)$ for IVM [13] defined this way could thus validate our own results. Estimates based on Gerstl [91] and Sabljić et al. [92] come closest to this value. This indicates a possible correlation which could also apply to the other three antiparasitics, especially when using $\log K_{\mathrm{OC}}$ from sediment studies.

The $\log K_{\mathrm{OW}}$ is a hydrophobicity indicator linked to a molecule itself and it is immaterial whether said molecule would be released into soil, sediment, or other parts of the environment. Thus, an implied distinction between a 
Table 4 Estimations for log $K_{\text {ow }}$ of the investigated antiparasitics based on RTO log $K_{\text {OC }}$ reported in this work. Compiled $K_{\text {OC }}-K_{\text {ow }}$ correlations are sorted chronologically

\begin{tabular}{|c|c|c|c|c|}
\hline \multirow[t]{2}{*}{$\begin{array}{l}\text { Substance in } \\
\text { soils }\end{array}$} & \multicolumn{4}{|c|}{$\begin{array}{l}\text { Estimated log } K_{\mathrm{ow}} \text { calculated from reported } \\
K_{\mathrm{oc}}-K_{\mathrm{OW}} \text { correlations }\end{array}$} \\
\hline & $\begin{array}{l}\text { Karickhoff } \\
{[68]^{\mathrm{a}}}\end{array}$ & Gerstl [91] & $\begin{array}{l}\text { Sabljić } \\
\text { et al. } \\
{[92]^{c}}\end{array}$ & Baker $[93]^{d}$ \\
\hline$A B A$ & 4.02 & 4.37 & 4.36 & 3.92 \\
\hline DOR & 4.32 & 4.81 & 4.73 & 4.25 \\
\hline IVM & 4.52 & 5.09 & 4.96 & 4.46 \\
\hline MOX & 5.14 & 6.00 & 5.73 & 5.15 \\
\hline \multicolumn{5}{|c|}{ Substance in sediments } \\
\hline $\mathrm{ABA}$ & 4.42 & 4.96 & 4.85 & 4.36 \\
\hline DOR & 4.53 & 5.11 & 4.98 & 4.47 \\
\hline IVM & 5.01 & 5.81 & 5.57 & 5.00 \\
\hline MOX & 5.38 & 6.34 & 6.01 & 5.40 \\
\hline
\end{tabular}

a Original equation: $\log K_{\mathrm{oc}}=0.989 * \log K_{\mathrm{ow}}-0.346$ (for hydrophobic chemicals)

${ }^{\mathrm{b}}$ Original equation: $\log K_{\mathrm{oc}}=0.679 * \log K_{\mathrm{ow}}+0.663$ (for non-specific chemicals)

${ }^{c}$ Original equation: $\log K_{\mathrm{oc}}=0.81 * \log K_{\mathrm{ow}}+0.10$ (for predominantly hydrophobic chemicals)

${ }^{d}$ Original equation: $\log K_{\mathrm{oc}}=0.903 * \log K_{\mathrm{ow}}+0.094$ (for non-specific chemicals)

$\log K_{\mathrm{OW}}$ based on either soil or sediment sorption coefficients remains theoretical. Still, with the derived $\log K_{\mathrm{OC}}$ data, all four substances displayed a $\log K_{\mathrm{OW}}>4$ except for ABA in soils if calculated according to Baker [93]. This may indicate that in regulatory terms all drugs could carry a potential for bioaccumulation to occur in the environment [12] with IVM and MOX giving the biggest cause for concern in this regard. Then again, Tolls [11] described that the prediction from $\log K_{\mathrm{OW}}$ could underestimate the $\log K_{\mathrm{OC}}$. A reverse estimate based solely on sorption coefficients could therefore overestimate the log $K_{\text {Ow. }}$. However, Tolls [11] also concluded that for large hydrophobic molecules such as avermectins $\log K_{\mathrm{OC}}$ predictions would not deviate to a great extent which bolsters our predictions. The use of these estimations is to provide a general indication of hydrophobicity based on a common dataset of $K_{\mathrm{OC}}$ for all four substances.

Although more sophisticated approaches such as quantitative structure-activity relationships can be employed, $K_{\mathrm{OC}}$ to $K_{\mathrm{OW}}$ correlations can be useful if transparent and verifiable $K_{\mathrm{OW}}$ data are not available. Benefits are conceivable since the $K_{\mathrm{OW}}$ is also an important parameter for environmental risk assessments. Prichard et al. [15] provided a consistent dataset of $K_{\mathrm{OW}}$ estimations and used atomic parameters to calculate the following order of coefficients $\left(\log K_{\mathrm{OW}}\right)$ : EPR (4.4), IVM (4.8), ABA (5.3), DOR (5.6), MOX (6.0), and selamectin (6.3). Fittingly, selamectin was also assessed by Römbke et al. [13] with the slow-stirring method to indicate a $\log K_{\mathrm{OW}}$ of 6.0 $( \pm 0.7)$. Meanwhile, risk assessments for VMPs rely on robust data. Dissipation of macrocyclic lactone antiparasitics varies depending on climate and field conditions $[20,66,94]$ and a harmonized dataset on experimental $K_{\text {Ow }}$ and their environmental fate properties would be admirable.

A limitation of sorption studies with pharmaceutical compounds is the transferability to the environmental reality. The $K_{\mathrm{OC}}$ concept does not account for organic matter composition and may misinterpret substance behavior at particular locations, especially in sediments. If enough data is available, a multiple linear regression with all soil/sediment properties is always advisable. Also, while for IVM low metabolization has been described in animal species [14], human metabolism of IVM could be more pronounced [81]. Transformation products of varying size and polarity could hypothetically demonstrate different sorption behavior in soils and sediments. Investigating the abundance and fate of antiparasitic metabolites after excretion is thus a logical future task. In light of the upcoming European veterinary regulation [Regulation (EU) 2019/6] steadfast assessments will gain in importance [39]. Our estimations of $\log K_{\mathrm{OW}}$ based on $\log K_{\mathrm{OC}}$ highlight the possible $K_{\mathrm{OW}}$ discrepancies and a precarious aspect of regulatory decision-making: while data may appear insufficient, they may be the only data available.

\section{Conclusions}

The investigated antiparasitics show strong sorption to the organic matter of soils and also sediments. Sorption strength in general (as $K_{\mathrm{D}}$ ) and normalized to organic carbon (as $K_{\mathrm{OC}}$ ) is characterized by the order: $\mathrm{ABA}<\mathrm{DOR}<\mathrm{IVM}<<\mathrm{MOX}$. Exemplary desorption from soils indicates mostly irreversible sorption processes and follows the same rationale with MOX showing the lowest transfer back into the liquid phase. The applied SPE-HPLC method with fluorescence detection is suitable for reliable quantification of all four analytes at once.

The consequent use of linear modeling with constrained intercepts allows to derive transparent and comparable sorption coefficients and facilitates future referral to our dataset. A variety of $K_{\mathrm{OW}}$ estimates urges to re-assess this important regulatory parameter with the appropriate technique. While for IVM and MOX our findings suggest the need to examine potential aquatic or terrestrial bioaccumulation, the medical and economic benefits of all four pharmaceuticals must not be denied. It is thus desirable to elaborate on their environmental fate and also include sediment-dwelling organisms in frameworks for toxicity testing. In perspective, risk mitigation 
measures for macrocyclic lactones should be improved to make antiparasitics a luminous example for the sustainable use of veterinary pharmaceuticals.

\begin{abstract}
Abbreviations
ABA: Abamectin; ACN: Acetonitrile; DOR: Doramectin; EMA: European Medicines Agency; EPR: Eprinomectin; EU: European Union; $f_{\mathrm{OC}}$ : Organic carbon fraction of the soil/sediment; HLNUG: Hessian Agency for Nature Conservation, Environment and Geology; IVM: Ivermectin; $K_{\mathrm{D}}$ : Distribution coefficient; $K_{\mathrm{OC}}:$ Organic carbon-water partition coefficient; $K_{\mathrm{O} \text { ow: }}$ Octanol-water partition coefficient; LOD: Limit of detection; LOQ: Limit of quantification; MOX: Moxidectin; OC: Organic carbon; OECD: Organisation for Economic Co-operation and Development; OLS: Ordinary least squares regression; \%OC: Weight percentage of soil/sediment organic carbon; RTO: Regression through the origin; SE: Standard error; VMPs: Veterinary medicinal products.
\end{abstract}

\section{Supplementary Information}

The online version contains supplementary material available at https://doi. org/10.1186/s12302-021-00513-y.

Additional file 1: Table S1. Analyte recovery (\%) when subjected to the presented SPE procedure compared to directly measured standards. Table S2. Output (OriginPro 2020b) of the multiple linear regression with transformed $K_{D}$ values and soil properties. Table S3. Supplemental data for Fig. 2. Individual soil $K_{D}$ values $(\mathrm{mL} / \mathrm{g})$. Table S4. Supplemental data for Fig. 3. Individual sediment $K_{D}$ values $(\mathrm{mL} / \mathrm{g})$. Figure $\mathrm{S}$. Chromatogram of standard solution with all 4 analytes (Abamectin, ABA; Doramectin, DOR; Ivermectin, IVM; Moxidectin, MOX). Figure S2. Chromatogram of the extracted aqueous soil solution with all 4 analytes (Abamectin, ABA; Doramectin, DOR; Ivermectin, IVM; Moxidectin, MOX).

\section{Acknowledgements}

German soil samples were obtained through a cooperation with the Hessian Agency for Nature Conservation, Environment and Geology (HLNUG) which included technical discussions. Advice on linear sorption models was provided by Dr. Mark A. Chappell (personal communication).

We tried using a colorblind barrier-free color pallet for figures and utilized information from https://jly.uni-koeln.de/color/ compiled by Masataka Okabe and Kei Ito. The graphical abstract contains images from Servier Medical Art by Servier (https://smart.servier.com/). Chemical structures were drawn using BIOVIA Draw Academic 20.1 (Dassault Systèmes, https://www.3ds.com/). We further acknowledge the practical work of all dedicated students contributing to this study, especially: Edwina Böttcher, Lisa Gietmann, Sarah Hörchner, Johannes Junck, Daniel Frank Kaiser, Leoni König, Hossay Lalandary, Sabrina Quanz, and Patrick Widrinski.

\section{Disclaimer}

The study investigates the sorption of veterinary antiparasitics in soils and sediments for academic purposes. The aim of the article is to provide information on the environmental fate of these pharmaceuticals. The article may not be understood as a regulatory assessment.

\section{Authors' contributions}

APH wrote the first draft of the manuscript. RAD conceived and designed the study. RAD, MW, LB, and APH conceived and designed experiments. TZ and APH performed experiments. APH, TZ, and RAD performed statistical analyses. $\mathrm{SJ}, \mathrm{YEM}$, and AD took Moroccan samples and performed additional chemical analyses. All authors read and approved the final manuscript.

\section{Funding}

Open Access funding enabled and organized by Projekt DEAL. The authors gratefully acknowledge financial support by the German Federal Ministry of Education and Research (BMBF) for the FETCH project, grant 01DH17038. The BMBF had no role in the design of the study, in collection, analysis, and interpretation of data, or in manuscript preparation.

\section{Availability of data and materials}

All relevant data and material are included in this published article and its supplementary information (SI). Other data and calculation tools for this research are available upon reasonable request from the authors A. P. Heinrich and R-A. Düring.

\section{Declarations}

Ethics approval and consent to participate

Not applicable.

\section{Consent for publication}

Not applicable.

\section{Competing interests}

The authors declare that they have no competing interests.

\section{Author details}

${ }^{1}$ Institute of Soil Science and Soil Conservation, Research Center for Biosystems, Land Use and Nutrition (iFZ), Justus Liebig University Giessen, Giessen, Germany. ${ }^{2}$ Laboratory of Materials, Nanotechnology and Environment (LMNE), Faculty of Sciences, Mohammed V University in Rabat, Av Ibn Battouta Agdal, BP1014 Rabat, Morocco. ${ }^{3}$ Département Des Sciences Fondamentales Et Appliquées, Institut Agronomique Et Véterinaire Hassan II, Rabat, Morocco.

Received: 11 March 2021 Accepted: 10 June 2021

Published online: 02 July 2021

\section{References}

1. Burg RW, Miller BM, Baker EE, Birnbaum J, Currie SA, Hartman R, Kong YL, Monaghan RL, Olson G, Putter I, Tunac JB, Wallick H, Stapley EO, Oiwa R, Omura S (1979) Avermectins, new family of potent anthelmintic agents: producing organism and fermentation. Antimicrob Agents Chemother 15:361-367. https://doi.org/10.1128/aac.15.3.361

2. Geary TG, Conder GA, Bishop B (2004) The changing landscape of antiparasitic drug discovery for veterinary medicine. Trends Parasitol 20:449-455. https://doi.org/10.1016/j.pt.2004.08.003

3. Shoop WL, Mrozik H, Fisher MH (1995) Structure and activity of avermectins and milbemycins in animal health. Vet Parasitol 59:139-156. https:// doi.org/10.1016/0304-4017(94)00743-V

4. Crump A, Ōmura S (2011) Ivermectin, 'wonder drug'from Japan: the human use perspective. Proc Jpn Acad Ser B 87:13-28. https://doi.org/10. 2183/pjab.87.13

5. WHO (2019) World Health Organization model list of essential medicines, 21st list: licence: CC BY-NC-SA 3.0 IGO, Geneva, Switzerland

6. Chaccour CJ, Kobylinski KC, Bassat Q, Bousema T, Drakeley C, Alonso P, Foy BD (2013) Ivermectin to reduce malaria transmission: a research agenda for a promising new tool for elimination. Malar J 12:153. https://doi.org/ 10.1186/1475-2875-12-153

7. Billingsley P, Binka F, Chaccour C, Foy B, Gold S, Gonzalez-Silva M, Jacobson J, Jagoe G, Jones C, Kachur P, Kobylinski K, Last A, Lavery JV, Mabey D, Mboera D, Mbogo C, Mendez-Lopez A, Rabinovich NR, Rees S, Richards F, Rist C, Rockwood J, Ruiz-Castillo P, Sattabongkot J, Saute F, Slater H, Steer A, Xia K, Zullinger R (2020) A roadmap for the development of ivermectin as a complementary malaria vector control tool: the ivermectin roadmappers. Am J Trop M Hyg 102:3-24. https://doi.org/10.4269/ajtmh.19-0620

8. Crump A (2017) Ivermectin: enigmatic multifaceted 'wonder' drug continues to surprise and exceed expectations. J Antibiot 70:495-505. https:// doi.org/10.1038/ja.2017.11

9. Díaz-Cruz M, López de Alda, María J., Barceló D, (2003) Environmental behavior and analysis of veterinary and human drugs in soils, sediments and sludge. TrAC 22:340-351. https://doi.org/10.1016/S0165-9936(03) 00603-4

10. Rao PSC, Jessup RE (1983) Sorption and movement of pesticides and other toxic organic substances in soils. In: Nelson DW, Elrick DE, Tanji KK (eds) Chemical mobility and reactivity in soil systems. SSSA special publication, USA, pp 183-201 
11. Tolls J (2001) Sorption of veterinary pharmaceuticals in soils: a review. Environ Sci Technol 35:3397-3406. https://doi.org/10.1021/es0003021

12. EMA (2016) Guideline on environmental impact assessment for veterinary medicinal products in support of the VICH guidelines GL6 and GL38. EMEA/CVMP/ERA/418282/2005-Rev.1 Corr.1. London, United Kingdom

13. Römbke J, Duis K, Egeler P, Gilberg D, Schuh C, Herrchen M, Hennecke D, Hölzle LE, Heilmann-Thudium B, Wohde M, Wagner J, Düring R-A (2019) Comparison of the environmental properties of parasiticides and harmonisation of the basis for environmental assessment at the EU level. Final Report. Dessau-Roßlau, Germany

14. González Canga A, Sahagún Prieto AM, José Diez Liébana M, Martínez NF, Vega MS, Vieitez JJG (2009) The pharmacokinetics and metabolism of ivermectin in domestic animal species. Vet J 179:25-37. https://doi.org/ 10.1016/j.tvjl.2007.07.011

15. Prichard R, Ménez C, Lespine A (2012) Moxidectin and the avermectins: consanguinity but not identity. Int J Parasitol Drugs Drug Resist 2:134-153. https://doi.org/10.1016/j.ijpddr.2012.04.001

16. Ou L, Gannon TW, Arellano C, Polizzotto ML (2018) A global metaanalysis to predict atrazine sorption from soil properties. J Environ Qual 47:1389-1399. https://doi.org/10.2134/jeq2017.11.0429

17. Krogh KA, Søeborg T, Brodin B, Halling-Sørensen B (2008) Sorption and mobility of ivermectin in different soils. J Environ Qual 37:2202-2211. https://doi.org/10.2134/jeq2007.0592

18. Popova IE, Bair DA, Tate KW, Parikh SJ (2013) Sorption, leaching, and surface runoff of beef cattle veterinary pharmaceuticals under simulated irrigated pasture conditions. J Environ Qual 42:1167-1175. https://doi. org/10.2134/jeq2013.01.0012

19. Rath S, Pereira LA, Bosco SMD, Maniero MG, Fostier AH, Guimarães JR (2016) Fate of ivermectin in the terrestrial and aquatic environment: mobility, degradation, and toxicity towards Daphnia similis. Environ Sci Pollut R 23:5654-5666. https://doi.org/10.1007/s11356-015-5787-6

20. Dionisio AC, Rath S (2016) Abamectin in soils: analytical methods, kinetics, sorption and dissipation. Chemosphere 151:17-29. https://doi.org/10. 1016/j.chemosphere.2016.02.058

21. Litskas VD, Karamanlis XN, Batzias GC, Kamarianos AP (2011) Sorption of the antiparasitic drug eprinomectin in three soils. Chemosphere 82:193-198. https://doi.org/10.1016/j.chemosphere.2010.10.024

22. Litskas VD, Batzias GC, Paraskevas CG, Pavlatou-Ve A, Karamanlis XN (2016) Mobility of pharmaceutical compounds in the terrestrial environment: adsorption kinetics of the macrocyclic lactone eprinomectin in soils. Chemosphere 144:1201-1206. https://doi.org/10.1016/j.chemosphere. 2015.09.100

23. Rath S, Fostier AH, Pereira LA, Dioniso AC, de Oliveira Ferreira F, Doretto KM, Maniero Peruchi L, Viera A, de Oliveira Neto OF, Dal Bosco SM, Martínez-Mejía MJ (2019) Sorption behaviors of antimicrobial and antiparasitic veterinary drugs on subtropical soils. Chemosphere 214:111-122. https://doi.org/10.1016/j.chemosphere.2018.09.083

24. Sparks DL (2003) Environmental soil chemistry, 2nd edn. Academic Press, Amsterdam

25. Halley BA, Nessel RJ, Lu AYH, Roncalli RA (1989) The environmental safety of ivermectin: an overview. Chemosphere 18:1565-1572. https://doi.org/ 10.1016/0045-6535(89)90046-5

26. Merck \& Co., Inc. (1990) Environmental assessment IVOMEC ${ }^{\circledR}$ (ivermectin) pour-on for cattle: March 22, 1990. 2384-3|22|90, P.O. Box 2000. USA

27. Wislocki PG, Grosso LS, Dybas RA (1989) Environmental aspects of abamectin use in crop protection. In: Campbell WC (ed) Ivermectin and abamectin. Springer, NY, pp 182-200

28. ECHA (2010) Background document to the opinion of the committee for risk assessment on a proposal for harmonised classification and labeling of abamectin and avermectin B1a. Finland

29. Zoetis (2015) Safety data sheet-dectomax doramectin injectable solution $10 \mathrm{mg} / \mathrm{ml}$. https://www.zoetisus.com/contact/pages/product_infor mation/msds_pi/msds/Dectomax_Injectable.pdf. Accessed 19 Feb 2021

30. Fort Dodge Animal Health (1997) Environmental assessment_cydectin moxidectin $0.5 \%$ pour-on for cattle. https://animaldrugsatfda.fda.gov/ adafda/app/search/public/document/downloadEA/146. Accessed 19 Feb 2021

31. EMA 2017 Moxidectin Article-35 referral-Annex II scientific conclusions and grounds for amendment of the summaries of product characteristics, labelling and package leaflets. United Kingdom
32. EMA 2012 Prontax $10 \mathrm{mg} / \mathrm{ml}$ solution-Article 33 referral-Annex II. United Kingdom

33. Liebig M, Fernandez AA, Blübaum-Gronau E, Boxall A, Brinke M, Carbonell G, Egeler P, Fenner K, Fernandez C, Fink G, Garric J, Halling-Sørensen B, Knacker T, Krogh KA, Küster A, Löffler D, Cots MAP, Pope L, Prasse C, Römbke J, Rönnefahrt I, Schneider MK, Schweitzer N, Tarazona JV, Ternes TA, Traunspurger W, Wehrhan A, Duis K (2010) Environmental risk assessment of ivermectin: a case study. Integr Environ Assess Manag 6(Suppl):567-587. https://doi.org/10.1002/ieam.96

34. Davies I, Gillibrand P, McHenery J, Rae G (1998) Environmental risk of ivermectin to sediment dwelling organisms. Aquaculture 163:29-46. https:// doi.org/10.1016/S0044-8486(98)00211-7

35. OECD (2006) Test no. 123: partition coefficient (1-octanol/water): slowstirring method. OECD guidelines for the testing of chemicals, Section 1. OECD, France

36. U.S. EPA (2020) CompTox chemicals dashboard: query: 71827-03-7. https://comptox.epa.gov/dashboard/DTXSID8023181. Accessed 19 Feb 2021

37. Arnot JA, Arnot MI, Mackay D, Couillard Y, MacDonald D, Bonnell M, Doyle P (2010) Molecular size cutoff criteria for screening bioaccumulation potential: fact or fiction? Integr Environ Assess Manag 6:210-224. https:// doi.org/10.1897/IEAM_2009-051.1

38. EMA (2017) Moxidectin Article-35 referral_questions and answers on the environmental impact of moxidectin-containing veterinary medicines used in cattle, sheep and horses. EMA/587529/2017. United Kingdom

39. Fabrega J, Carapeto R (2020) Regulatory review of the environmental risk assessment of veterinary medicinal products in the European Union, with particular focus on the centralised authorisation procedure. Environ Sci Eur. https://doi.org/10.1186/s12302-020-00374-x

40. EC (2019) European Union strategic approach to pharmaceuticals in the environment. COM (2019) 128 final. Belgium

41. Lumaret J-P, Errouissi F, Floate K, Römbke J, Wardhaugh K (2012) A review on the toxicity and non-target effects of macrocyclic lactones in terrestrial and aquatic environments. Curr Pharm Biotechnol 13:1004-1060. https://doi.org/10.2174/138920112800399257

42. Finch D, Schofield H, Floate KD, Kubasiewicz LM, Mathews F (2020) Implications of endectocide residues on the survival of aphodiine dung beetles: a meta-analysis. Environ Toxicol Chem 39:863-872. https://doi. org/10.1002/etc.4671

43. Junco M, Iglesias LE, Sagués MF, Guerrero I, Zegbi S, Saumell CA (2021) Effect of macrocyclic lactones on nontarget coprophilic organisms: a review. Parasitol Res 120:773-783. https://doi.org/10.1007/ s00436-021-07064-4

44. Sanderson H, Laird B, Pope L, Brain R, Wilson C, Johnson D, Bryning G, Peregrine AS, Boxall A, Solomon K (2007) Assessment of the environmental fate and effects of ivermectin in aquatic mesocosms. Aquat Toxicol 85:229-240. https://doi.org/10.1016/j.aquatox.2007.08.011

45. Egeler P, Gilberg D, Fink G, Duis K (2010) Chronic toxicity of ivermectin to the benthic invertebrates Chironomus riparius and Lumbriculus variegatus. J Soils Sediments 10:368-376. https://doi.org/10.1007/s11368-010-0197-3

46. Mesa LM, Hörler J, Lindt I, Gutiérrez MF, Negro L, Mayora G, Montalto L, Ballent M, Lifschitz A (2018) Effects of the antiparasitic drug moxidectin in cattle dung on zooplankton and benthic invertebrates and its accumulation in a water-sediment system. Arch Environ Contam Toxicol 75:316-326. https://doi.org/10.1007/s00244-018-0539-5

47. Mesa L, Gutiérrez MF, Montalto L, Perez V, Lifschitz A (2020) Concentration and environmental fate of ivermectin in floodplain wetlands: an ecosystem approach. Sci Total Environ 706:135692. https://doi.org/10.1016/j. scitotenv.2019.135692

48. Kumirska J, Wagil M, Stolte S, Maksymiuk M, Puckowski A, Maszkowska J, Biak-Bieliska A, Caban M, Stepnowski P (2016) Anthelmintics in the aquatic environment: a new analytical approach. Curr Anal Chem 12:227-236. https://doi.org/10.2174/1573411012666151009193940

49. Novelli A, Vieira BH, Braun AS, Mendes LB, Daam MA, Espíndola ELG (2016) Impact of runoff water from an experimental agricultural field applied with Vertimec ${ }^{\circledR}$ 18EC (abamectin) on the survival, growth and gill morphology of zebrafish juveniles. Chemosphere 144:1408-1414. https://doi. org/10.1016/j.chemosphere.2015.10.004

50. Vasconcelos AM, Daam MA, de Resende JC, Casali-Pereira MP, Espíndola ELG (2017) Survival and development of bullfrog tadpoles in microcosms 
treated with abamectin. Ecotoxicology 26:729-737. https://doi.org/10. 1007/s10646-017-1804-5

51. Grant A, Briggs AD (1998) Use of ivermectin in marine fish farms: some concerns. Mar Pollut Bull 36:566-568. https://doi.org/10.1016/S0025326X(98)00032-0

52. Hong Y, Huang Y, Yang X, Zhang J, Li L, Huang Q, Huang Z (2020) Abamectin at environmentally-realistic concentrations cause oxidative stress and genotoxic damage in juvenile fish (Schizothorax prenanti). Aquat Toxicol 225:105528. https://doi.org/10.1016/j.aquatox.2020.105528

53. Horsberg TE (2012) Avermectin use in aquaculture. Curr Pharm Biotechnol 13:1095-1102. https://doi.org/10.2174/138920112800399158

54. Cannavan A, Coyne R, Kennedy D, Smith P (2000) Concentration of 22,23-dihydroavermectin B1a detected in the sediments at an Atlantic salmon farm using orally administered ivermectin to control sea-lice infestation. Aquaculture 182:229-240. https://doi.org/10.1016/S00448486(99)00259-8

55. Prasse C, Löffler D, Ternes TA (2009) Environmental fate of the anthelmintic ivermectin in an aerobic sediment/water system. Chemosphere 77:1321-1325. https://doi.org/10.1016/j.chemosphere.2009.09.045

56. Wohde M, Bartz J-O, Böhm L, Hartwig C, Keil BM, Martin K, Düring R-A (2017) Automated thin-film microextraction coupled to a flow-through cell: somewhere in between passive and active sampling. Anal Bioanal Chem 409:1975-1984. https://doi.org/10.1007/s00216-016-0145-1

57. Windell JT, Willard BE, Cooper DJ, Foster SQ, Knud-Hansen CF, Rink LP, Kiladis GN (1986) An ecological characterization of Rocky Mountain montane and subalpine wetlands. Biological Report 86(11). USA

58. Bruno MC, Bottazzi E, Rossetti G (2012) Downward, upstream or downstream? Assessment of meio- and macrofaunal colonization patterns in a gravel-bed stream using artificial substrates. Ann Limnol Int J Lim 48:371-381. https://doi.org/10.1051/limn/2012025

59. Sánchez-Bayo F, Wyckhuys KA (2019) Worldwide decline of the entomofauna: a review of its drivers. Biol Conserv 232:8-27. https://doi.org/10. 1016/j.biocon.2019.01.020

60. Diepens NJ, Koelmans AA, Baveco H, van den Brink PJ, van den HeuvelGreve MJ, Brock TCM (2017) Prospective environmental risk assessment for sediment-bound organic chemicals: a proposal for tiered effect assessment. Rev Environ Contam Toxicol 239:1-77. https://doi.org/10. 1007/398_2015_5004

61. OECD (2000) Test No. 106: Adsorption-desorption using a batch equilibrium method. OECD guidelines for the testing of chemicals, Section 1. OECD, Paris

62. Hamdaoui F, Aboubaker Alzwi S, Alibrahmi E, El Kharrim K, Belghyti D, Lofti N (2018) Physical and chemical diagnosis of lower Sebou river for agricultural use (GHARB-Morocco). Int J Environ Agric Res 4:56-64. https://doi.org/10.5281/zenodo.1188066

63. IUSS Working Group WRB (2015) World reference base for soil resources 2014, update 2015. International soil classification system for naming soils and creating legends for soil maps. World Soil Resources Reports No. 106. Italy

64. Folk RL (1954) The distinction between grain size and mineral composition in sedimentary-rock nomenclature. J Geol 62:344-359. https://doi. org/10.1086/626171

65. Fisher MH, Mrozik H (1989) Chemistry. In: Campbell WC (ed) Ivermectin and abamectin. Springer, NY, pp 1-23

66. Wohde M, Blanckenhorn WU, Floate KD, Lahr J, Lumaret J-P, Römbke J, Scheffczyk A, Tixier T, Düring R-A (2016) Analysis and dissipation of the antiparasitic agent ivermectin in cattle dung under different field conditions. Environ Toxicol Chem 35:1924-1933. https://doi.org/10.1002/etc. 3462

67. Chappell MA, Seiter JM, West HM, Miller LF, Negrete ME, LeMonte JJ, Porter BE, Price CL, Middleton MA (2020) Organic contaminant sorption parameters should only be compared across a consistent system of linear functions. Heliyon 6:e03511. https://doi.org/10.1016/j.heliyon.2020. e03511

68. Karickhoff SW (1981) Semi-empirical estimation of sorption of hydrophobic pollutants on natural sediments and soils. Chemosphere 10:833-846. https://doi.org/10.1016/0045-6535(81)90083-7

69. McCall PJ, Swann RL, Laskowski DA, Unger SM, Vrona SA, Dishburger HJ (1980) Estimation of chemical mobility in soil from liquid chromatographic retention times. Bull Environ Contam Toxicol 24:190-195. https:// doi.org/10.1007/BF01608096
70. Chiou CT, Kile DE (2000) Contaminant sorption by soil and bed sediment. is there a difference? Fact sheet-087-00. USA

71. ICH (2005) Harmonised tripartite guideline: validation of analytical procedures: text and methodology Q2(R1)

72. Krahe S, Düring R-A, Huisman JA, Horn AL, Gäth S (2006) Statistical modeling of the partitioning of nonylphenol in soil. Water Air Soil Pollut 172:221-237. https://doi.org/10.1007/s11270-005-9077-7

73. Grathwohl P (1990) Influence of organic matter from soils and sediments from various origins on the sorption of some chlorinated aliphatic hydrocarbons: implications on $K_{\text {oc }}$ correlations. Environ Sci Technol 24:1687-1693. https://doi.org/10.1021/es00081a010

74. Eisenhauer JG (2003) Regression through the origin. teach. Stat 25:76-80. https://doi.org/10.1111/1467-9639.00136

75. Jones RJA, Hiederer R, Rusco E, Montanarella L (2005) Estimating organic carbon in the soils of Europe for policy support. Eur J Soil Sci 56:655-671. https://doi.org/10.1111/j.1365-2389.2005.00728.x

76. Litskas VD, Karamanlis XN, Batzias GC, Tsiouris SE (2013) Are the parasiticidal avermectins resistant to dissipation in the environment? The case of eprinomectin. Environ Int 60:48-55. https://doi.org/10.1016/j.envint.2013. 07.017

77. Wohde M, Berkner S, Junker T, Konradi S, Schwarz L, Düring R-A (2016) Occurrence and transformation of veterinary pharmaceuticals and biocides in manure: a literature review. Environ Sci Eur 28:23. https://doi.org/ 10.1186/s12302-016-0091-8

78. Junker T, Atorf C, Berkner S, Düring R-A, Hennecke D, Herrchen M, Konrad S, Merrettig-Bruns U, Römbke J, Wagner J, Weinfurtner K (2020) Development of a test method for transformation of veterinary pharmaceuticals and biocides in anaerobic liquid manure. Environ Sci Eur. https://doi.org/ 10.1186/s12302-020-00323-8

79. Hora PI, Pati SG, McNamara PJ, Arnold WA (2020) Increased use of quaternary ammonium compounds during the SARS-CoV-2 pandemic and beyond: consideration of environmental implications. Environ Sci Technol Lett 7:622-631. https://doi.org/10.1021/acs.estlett.0c00437

80. Pooda HS, Rayaisse J-B, Hien DFdS, Lefèvre T, Yerbanga SR, Bengaly Z, Dabiré RK, Belem AMG, Sidibé I, Solano P, Mouline K (2015) Administration of ivermectin to peridomestic cattle: a promising approach to target the residual transmission of human malaria. Malar J 13(Suppl 1):496. https:// doi.org/10.1186/s12936-015-1001-z

81. Tipthara P, Kobylinski KC, Godejohann M, Hanboonkunupakarn B, Roth A, Adams JH, White NJ, Jittamala P, Day NPJ, Tarning J (2021) Identification of the metabolites of ivermectin in humans. Pharmacol Res Perspect 9:e00712. https://doi.org/10.1002/prp2.712

82. Pecenka JR, Lundgren JG (2019) Effects of herd management and the use of ivermectin on dung arthropod communities in grasslands. Basic Appl Ecol 40:19-29. https://doi.org/10.1016/j.baae.2019.07.006

83. Römbke J, Duis K (2018) Proposal for a monitoring concept for veterinary medicinal products with PBT properties, using parasiticides as a case study. Toxics. https://doi.org/10.3390/toxics6010014

84. Kaplan RM, Vidyashankar AN (2012) An inconvenient truth: global warming and anthelmintic resistance. Vet Parasitol 186:70-78. https://doi.org/ 10.1016/j.vetpar.2011.11.048

85. Gruber VF, Halley BA, Hwang S-C, Ku CC (1990) Mobility of avermectin B1a in soil. J Agric Food Chem 38:886-890. https://doi.org/10.1021/ff000 93a063

86. Mutavdžić Pavlović D, Glavač A, Gluhak M, Runje M (2018) Sorption of albendazole in sediments and soils: isotherms and kinetics. Chemosphere 193:635-644. https://doi.org/10.1016/j.chemosphere.2017.11.025

87. Roberts L, Boardman G, Voshell R (2009) Benthic macroinvertebrate susceptibility to trout farm effluents. Water Environ Res 81:150-159. https:// doi.org/10.2175/106143008×325854

88. Wang Di, Han B, Li S, Cao Y, Du X, Lu T (2019) Environmental fate of the anti-parasitic ivermectin in an aquatic micro-ecological system after a single oral administration. PeerJ 7:e7805. https://doi.org/10.7717/peerj. 7805

89. Piwoni MD, Keeley JW (1990) Ground water issue: basic concepts of contaminant sorption at hazardous waste sites. EPA/540/4-90/053. USA

90. Katritzky M, Lobanov K (2000) Structurally diverse quantitative structureproperty relationship correlations of technologically relevant physical properties. J Chem Inf Comput Sci 40:1-18. https://doi.org/10.1021/ci990 3206 
91. Gerstl Z (1990) Estimation of organic chemical sorption by soils. J Contam Hydrol 6:357-375. https://doi.org/10.1016/0169-7722(90)90034-E

92. Sabljić A, Güsten H, Verhaar H, Hermens J (1995) QSAR modelling of soil sorption. Improvements and systematics of log $K_{\mathrm{OC}}$ vs. $\log K_{\mathrm{OW}}$ correlations. Chemosphere 31:4489-4514. https://doi.org/10.1016/00456535(95)00327-5

93. Baker JR (1997) Evaluation of estimation methods for organic carbon normalized sorption coefficients. Water Environ Res 69:136-145. https:// doi.org/10.2175/106143097X125281
94. de Oliveira Ferreira F, Porto RS, Rath S (2019) Aerobic dissipation of avermectins and moxidectin in subtropical soils and dissipation of abamectin in a field study. Ecotoxicol Environ Saf 183:109489. https://doi.org/10. 1016/j.ecoenv.2019.109489

\section{Publisher's Note}

Springer Nature remains neutral with regard to jurisdictional claims in published maps and institutional affiliations.

\section{Submit your manuscript to a SpringerOpen ${ }^{\circ}$ journal and benefit from:}

- Convenient online submission

- Rigorous peer review

- Open access: articles freely available online

- High visibility within the field

- Retaining the copyright to your article

Submit your next manuscript at $\boldsymbol{\nabla}$ springeropen.com 